\title{
A educação no horizonte da construção linguística
}

\author{
CLENIO LAGO \\ Universidade do Oeste de Santa Catarina, \\ São Miguel do Oeste, SC, Brasil \\ MAURICIO JOÃO FARINON \\ Universidade do Oeste de Santa Catarina, \\ São Miguel do Oeste, SC, Brasil
}

RESUMO

Este artigo tem como problemática e objetivo central a reflexão sobre o sentido da educação, com base na teoria crítica de Adorno e na perspectiva hermenêutica de Gadamer, as quais se situam em uma corrente filosófica denominada pós-metafísica. A quebra dos referencias tidos até então como seguros afeta o projeto educacional ocidental no que se refere à sua finalidade, uma vez que indicava fins definidos de modo absolutamente universais e sem considerar a dinamicidade da experiência. Tais autores se deparam com o problema da formação nesse novo contexto, marcado pelo retorno do interesse ao ser humano em sua contingência histórica e como constituidor de linguagem em âmbito intersubjetivo. Nesse intuito, serão resgatadas as proposições dos filósofos em questão para, em seguida, estabelecer o diálogo entre eles, propondo um sentido para a educação no século XXI. Ambos oferecem elementos que, se articulados, apresentam proposições significativas aos desafios educacionais do mundo contemporâneo, ao assumirem o diálogo, a linguagem e a construção como elementos educativos.

\section{PALAVRAS-CHAVE}

educação; linguagem; experiência formativa; hermenêutica; Adorno; Gadamer. 


\title{
EDUCATION ON THE HORIZON OF LINGUISTIC CONSTRUCTION
}

\begin{abstract}
This article issue and central objective is a thinking on the meaning of education, based on Adorno's critical theory and Gadamer's hermeneutic perspective, which lie in a philosophical movement called post-metaphysical. The breakdown of references taken so far as safe affect the Western educational project in its telos, since it was based on a priori assumptions. Such authors are faced with the problem of training in this new context, marked by the return of interest to human beings in their historical contingency and as language constitutor in intersubjective context. To that end, the propositions of the philosophers in question will be redeemed to then establish the dialogue between them, suggesting a direction for education in the twenty-first century. Both offer elements which, if articulated, present significant propositions to educational challenges of the contemporary world when they assume the dialogue, language and construction as educational elements.
\end{abstract}

\section{KEYWORDS}

education; language; formative experience; hermeneutics; Adorno; Gadamer.

\section{LA EDUCACIÓN EN EL HORIZONTE DE LA CONSTRUCCIÓN LINGÜÍSTICA}

\section{RESUMEN}

Este artículo tiene como problemática y objetivo central la reflexión sobre el sentido de la educación con base en la teoría crítica de Adomo y en la perspectiva hermenéutica de Gadamer, las cuales se sitúan en una corriente filosófica denominada posmetafísica. La quiebra de los referenciales obtenidos hasta entonces como seguros afectan el proyecto educacional occidental en su telos, una vez que este estuvo basado en presupuestos considerados a priori. Tales autores se deparan con el problema de la formación en ese contexto, marcado por el retorno del interés por el ser humano en su contingencia histórica y como contituyente de lenguaje en ámbito intersubjetivo. En ese intuito, serán rescatadas las proposiciones de los filósofos en cuestión para, tras eso, establecer el diálogo entre ellos, proponiendo un sentido para la educación en el siglo XXI. Ambos ofrecen elementos que, si articulados, presentan proposiciones significativas a los desafíos educacionales del mundo contemporáneo, al asumir el diálogo, el lenguaje y la construcción, como elementos educativos.

\section{PALABRAS CLAVE}

educación; lenguaje, experiencia formativa; hermenéutica; Adorno; Gadamer. 


\section{INTRODUÇÃO}

Diante da multiplicidade e da dinamicidade, os gregos buscam referenciais que possibilitem certezas e instituem a metafísica como um lugar fora da areia movediça da contingência, situação em que os valores passam a ser alcançados e delineados pela razão. Na Idade Média, subsumido pela teologia, o télos educativo na forma de crença em Deus, justificada aos moldes do modelo neoplatônico, situa-se, também, no horizonte da metafísica. Se os ideais éticos gregos buscam plena e perfeita realização humana a ser obtida pela razão; a tradição cristã traz ideais em que o homem depende totalmente de um Deus único e criador, que se revela como verdadeiro fim. Com a crise do paradigma medieval, busca-se na razão objetiva, na razão científica, o referencial de certeza; razão esta constituída no âmbito do sujeito transcendental como razão pura que abandona a causa transcendente para, com base em si mesma, postular os referenciais transcendentais. Agora o sujeito do conhecimento deve aparecer no processo com sua universalidade, deixando de lado suas particularidades. Mas os efeitos históricos da razão, pretensamente pura, não se mostram tão razoáveis, e eis que entra em crise a razão moderna, revelando-se com ela os limites do sujeito moderno e suas certezas.

O que ousamos chamar de crise da modernidade é, na verdade, a crise do modo metafísico de pensar, o qual separa o sujeito do objeto, o homem da natureza, a teoria da prática, aquele que sabe daquele que não sabe. Essas provocações, juntamente com os desmandos da razão moderna, trouxeram necessidade de repensar a razão, fazer o retorno crítico sobre si mesmo, no sentido de realizar a dialética do esclarecimento; ocasionaram também a necessidade de buscar novos fundamentos, justificativas ao saber, sem cair no dogmatismo nem no relativismo.

Duas grandes posturas se abrem como possibilidade de resposta: uma que, constituída desde a Escola de Frankfurt e tecendo fortes críticas à razão moderna, busca rearticular o projeto de esclarecimento sobre outra base, não mais no sujeito transcendental, mas articulada sobre o núcleo histórico-experiencial; em Adorno, essa postura crítica assume a característica de comunicação entre diferentes no âmbito da construção de um conteúdo de verdade, o qual, por ser um conteúdo concreto, renova-se constantemente pela experiência. A outra postura é constituída no horizonte das contribuições de Heidegger e desemboca, especialmente, em Gadamer, com a hermenêutica filosófica; este último postula o diálogo profundo entre as diferentes tradições, situação em que as próprias regras do diálogo entram em jogo e a verdade aparece ao longo do processo como histórica, pois não é de nenhum dos interlocutores, mas surge no próprio diálogo.

Esses dois grandes filósofos são preocupados com os rumos da humanidade, com especial atenção à educação. Adorno pensa a educação como o ato de produzir a consciência verdadeira, com vistas ao ideal de emancipação do ser humano. Gadamer revisa a tradição à luz dos desafios contemporâneos da educação, no horizonte da 
hermenêutica filosófica como autoformação, que se efetiva no diálogo profundo do homem consigo mesmo desde o viger do outro.

É fundamental o permanente esforço teórico e prático direcionado ao mundo educacional, visto que os antigos referenciais ruíram e corremos os riscos do dogmatismo e do ceticismo. Não são poucos os desafios que professores, pais, sociedade, encontram na condução das gerações mais jovens e, até mesmo, na condução dos rumos da própria existência individual. A ruptura com a metafísica levou à crise da autoridade, nos modelos de vida válidos universalmente; inclusive, de modo fácil podemos cair no problema da ausência de qualquer referencial, como o da própria subjetividade.

Também é visível que o "poder" do cargo ocupado, da autoridade concedida hierarquicamente, hoje, sofre de insuficiência no ditar das normas de conduta. $\mathrm{E}$ isso é fruto de uma concepção que se inicia, de modo enfático, em Kant, mas encontra decisiva ressonância na contemporaneidade: ou a autoridade é esclarecida, ou se torna retrógrada, nociva. Diante disso é que se legitima este estudo, pois é de extrema importância repensar o que significa educar em tempos caracterizados como pós-metafísicos, a fim de lançar luzes sobre o processo formal e informal de ensino, suas políticas, seus currículos, suas didáticas.

O problema norteador, que originou esta investigação e norteia esta produção é: a partir do diálogo estabelecido entre a teoria crítica de Adorno e a perspectiva hermenêutica de Gadamer, em que termos a educação pode responder às exigências que envolvem a formação do ser humano?

Com o objetivo de indicar o sentido da educação por meio do desafio de construção linguística, o texto está dividido em três blocos. No primeiro, serão apresentadas as proposições de Adorno e seu ideal de geração das experiências formativas. No segundo, trazemos Gadamer e suas investigações sobre hermenêutica. No terceiro bloco textual, pontuamos os desafios que envolvem a formação, dirigindo o argumento para a importância da intersubjetividade na constituição do si. Nesta última parte, visualiza-se a construção e autoconstrução pela linguagem, o plasmar linguístico, por meio do qual é possível uma resposta à pergunta acima indicada.

\section{AS PROPOSIÇÕES DE ADORNO}

O ponto de partida para esta primeira parte do ensaio encontra na Metafísica de Aristóteles seu conceito fundamental. Partimos, então, da Grécia Antiga, mas nos inscrevemos na pós-modernidade, época caracterizada pelo rompimento com a metafísica. $\mathrm{O}$ referencial teórico é posto em Adorno, apontando para a formação do sujeito centrado na "comunicação do diferenciado", livre da pretensão de domínio.

Porém, ao falar em sujeito, é necessário entender seu sentido originário para, então, adentrarmos em sua ressignificação contemporânea. Sujeito, enquanto fundamento primeiro e origem de todo movimento, é conceito aristotélico. Portanto, em 
períodos anteriores, é duvidoso querer encontrar um princípio interno tão forte, se autores como Francis Wolff e Bruno Snell têm razão ao afirmarem que o espírito foi uma descoberta da cultura grega com ênfase às contribuições de Sócrates, Platão e Aristóteles. Todavia, é neste último que se encontra a alusão plena a esse princípio interno.

Com Aristóteles, o princípio do movimento ou causa motora não está em nenhuma instância, a não ser no próprio ente inscrito no mundo. Esse movimento de esclarecimento da razão centrada em si mesma demarca um retorno: se Platão nos faz sair da caverna para vislumbrar a luz e, então, termos o conhecimento do ser ou causa perfeita ideal em um outro mundo - o inteligível-, Aristóteles aponta para o interior da condição concreta do ente inscrito no mundo, ao dizer que o ser não se encontra em nenhum outro lugar a não ser na natureza própria (mundo sensível, apesar de ele mesmo ser metafísico, ou seja, dado não físico/concreto), em que é possível encontrar o substrato essencial de tudo o que há.

Na Metafísica, esse substrato essencial é posto por Aristóteles como um dos sentidos de substância. Ele é definido pelo autor como a essência, o universal, o gênero e o sujeito: "E o sujeito é aquilo sobre o qual são ditas as demais coisas, sem que ele, por sua vez, seja dito de outra” (Aristóteles, 1982, VII, 3, 1028b, p. 326, tradução nossa). Essa concepção encontra em seu centro a indicação de um elemento fundamental, a noção de determinação, condição para qualquer conhecimento. Nada é possível dizer sem considerar essa origem epistemológica, que em Aristóteles é a substância, identificada em um sentido com o sujeito. Substância é sujeito, em seu sentido enfático, a origem de todo o devir, força originária e que é, legitimamente, em-si. Os atributos somente predicam algo em referência a um sujeito; no caso, o sujeito congregador das predicações/determinações é a substância, e aquelas não existem fora desta. $\mathrm{Ou}$ seja, somente são em atribuição.

Esse elemento determinante, embora não esteja determinado, serve de origem ou suporte para todas as modificações que venha a sofrer, sendo chamado por Aristóteles de hypokeimenon ou sujeito. Em referência ao termo, convém esclarecer que, para Gadamer (2007b, p. 11), “[...] a palavra significa 'aquilo que se encontra na base'. É assim que a palavra vem ao nosso encontro na física e na metafísica aristotélicas [...] e significa aquilo que se encontra inalteravelmente à base da mudança de todas as transformações".

Partindo desse pressuposto conceitual, é possível vislumbrar um problema que consideramos essencial: até que ponto podemos ser considerados sujeitos. A concepção metafísica aristotélica aponta para um princípio interno capaz de mover, de ser causa da atualização da potência. É algo originário que não carrega influência causal externa a si mesmo, é apenas influência para todo derivado.

Assim sendo, a dúvida sobre o alcance dessa concepção de sujeito em relação ao ser humano revela-se pertinente. $O$ ponto de partida dessa discussão se insere numa época de administração da cultura, pois vivemos uma época na qual não é possível 
dizer que o pensamento resiste a toda forma de dominação, como um território impossível de ser invadido e controlado - se é que um dia o foi. Quando a cultura padronizada padroniza comportamentos, reações e sentimentos, torna-se evidente o controle objetivo do pensamento, contraponto imediato ao princípio interno denominado por Aristóteles hypokeimenon. Desse modo, convém questionar: até que ponto somos o sujeito, o princípio do movimento, a causa motora dos nossos próprios atos? Desses fatores surge, então, a necessidade de reflexão sobre a emancipação como característica a partir da qual podemos pensar o sujeito e a formação da subjetividade, enquanto força interna própria ao indivíduo.

\section{O CRITÉRIO DE EMANCIPAÇÃO E AS EXPERIÊNCIAS FORMATIVAS: ADORNO E O SENTIDO DE EDUCAÇÃO}

Somente podemos ser considerados sujeitos - no sentido forte da palavra, conforme exposto anteriormente - quando estamos aptos a ser lei para nós mesmos. Esse ideal kantiano de autonomia, o qual não é abstraído por Adorno, remete ao critério da autodeterminação. Sendo a autonomia, a autodeterminação, o critério para ser sujeito, é possível falar que "o professor precisa ter clareza quanto a que sua tarefa principal consiste em se tornar supérfluo” (Adorno, 2003, p. 177).

Essa afirmação, considerada de modo imediato, pode causar certo mal-estar principalmente no meio pedagógico. No entanto, um processo formativo que não considera tal critério na sua realização está condenado ao fracasso. Diante de métodos, estratégias, grandes objetivos intelectuais, o princípio de vir a ser supérfluo deve estar no centro do pensar e do fazer educativo. No sentido amplo da palavra educação, isso se aplica incisivamente, pois toda instância formativa (seja ela familiar, escolar, religiosa, política...) deveria promover a ausência de vínculos de dependência. Em última palavra, poder formar sujeitos: ideal de emancipação suprema, porém não como um estado de permanência alcançado. Qualquer vínculo de dependência é suspeito de ideologia, pois atribui um poder demasiadamente forte sobre alguém, a ponto de torná-lo submetido a vontades alheias - o que não condiz com a noção de sujeito enquanto aquele que determina seu próprio movimento.

Adorno (idem, p. 124) não usa a terminologia vínculos de dependência, mas sim "vínculos de compromisso", e os considera uma falsidade:

considero ser uma ilusão imaginar alguma utilidade no apelo a vínculos de compromisso ou até mesmo na exigência de que se restabeleçam vinculações de compromisso para que o mundo e as pessoas sejam melhores. A falsidade de compromissos que se exige somente para que provoquem alguma coisa - mesmo que esta seja boa -, sem que eles sejam experimentados por si mesmos como sendo substanciais para as pessoas.

O problema posto pelo autor de Educação e emancipação é que os compromissos podem representar não um bem em si mesmos, mas ter em vista benefícios pessoais. 
Esse problema já é apontado por Kant na Fundamentação da metafísica dos costumes (Kant, 2008, BA 8), quando, nas investigações sobre a fixação do princípio moral, põe de lado as ações conforme o dever, pois nessas o móbil da ação está no interesse do agente, portanto, uma intenção egoísta. O único vínculo é o interesse em tal finalidade, estando nossos compromissos voltados somente a esse télos. Usamos o termo vinculos de dependência por ter um significado decisivo na emancipação. Ser humano dependente é oposto a seres emancipados; quando os vínculos geram dependência, não há liberdade de realizar experiências próprias sem a tutela daqueles de quem somos dependentes.

Consequentemente, o ser humano fica impossibilitado de reclamar a si mesmo o papel de sujeito. Então, ele passa a ser qualquer outro, podendo, inclusive, ser entidade desprovida de subjetividade, como são os casos de ideologias, as estruturas de dominação, a indústria da cultura, a própria era de realidade virtual. Problema não menos sério é o fato de pessoas estarem à mercê de se tornar entidades desprovidas de subjetividade, no sentido de serem totalmente determinadas externamente, não pensarem fora dos parâmetros considerados normais por uma possível ordem estabelecida, a qual reclama para si a função de sujeito.

Nesse contexto é que está inscrita a educação, para Adorno, enquanto "produção de uma consciência verdadeira" (Adorno, 2003, p. 141), preparando as mentes e, consequentemente, os sujeitos, para a "superação permanente da alienação" (idem, p. 148). O conceito consciência remete a um aumento no grau de experiências formativas, e, nesse aumento, está a condição de possibilidade para a emancipação. Consciência é

o pensar em relação à realidade, ao conteúdo - a relação entre as formas e estruturas do pensamento do sujeito e aquilo que este não é. Este sentido mais profundo de consciência ou faculdade de pensar não é apenas o desenvolvimento lógico formal, mas ele corresponde literalmente à capacidade de fazer experiências. Eu diria que pensar é o mesmo que fazer experiências intelectuais. Nesta medida e nos termos que procuramos expor, a educação para a experiência é idêntica à educação para a emancipação. (idem, p. 151)

Como o fim da educação é a produção da consciência verdadeira, percebemos, com base no conceito exposto acima, que o único modo de garantir o desenvolvimento desta é a permanência na relação com aquilo que não somos, com aquilo que o pensamento não é. Estamos diante do critério adorniano de elevação do nível de experiência. Em termos educacionais, a sala de aula é o espaço em que a convivência permanente, a experiência permanente, pode encontrar seu máximo incentivo. Nela o aluno pode, incisivamente, aprender a conviver com a alteridade, com o outro, e assim entender o que significa permanecer em relação com o diferente. Os próprios 
currículos ${ }^{1}$ deveriam considerar esse critério de relação com o mundo e permanente relação como condição para o conhecimento, para a consciência, em suas propostas formativas.

Entretanto, ao fazermos essa discussão, podemos perceber o oposto, ou seja, as condições em função das quais ocorre o empobrecimento das experiências, causa do tão baixo nível de formação do ser humano que se quer sujeito. Remetemos à preocupação estética de Adorno no que se refere à formação escolar. Deveríamos ter preocupação com aquilo que as crianças têm de defasagem, aquilo que, muitas vezes, não conseguem aprender: "o indescritível empobrecimento do repertório de imagens, da riqueza de imagines sem a qual elas crescem, o empobrecimento da linguagem e de toda a expressão", dirigindo o olhar a esse problema para "discutir se a escola não pode assumir esta tarefa" (Adorno, 2003, p. 146).

Esse olhar que recai sobre as instituições de ensino, propondo o desafio de elas serem o espaço no qual esse repertório mental de imagens, de linguagem, encontraria seu pleno desenvolvimento, é plenamente aceitável. Enfaticamente, tais instituições não podem se abster dessa tarefa, em vista do critério qualitativo que permeia a educação, para aquém dos índices de aprovação ou desaprovação, da ampliação de espaços físicos (sem, é claro, abstrair-se da importância de tais critérios). No momento em que a escola assume a tarefa de gerar esse enriquecimento de imagens e de linguagem, a preocupação recai sobre a ampliação mental, a ampliação dos referenciais interpretativos do mundo, ampliação da capacidade de realizar experiências no mundo e, em linguagem adorniana, a produção da consciência verdadeira.

Nas experiências formativas, a consciência entra em confronto não apenas consigo mesma, mas, primordialmente, com o outro, pressupondo a renovação dessa experiência. Isso não deve ser posto com base em um critério puramente conceitual, pois, neste, a tarefa é de compreensão segura e estável, o que é impossível por meio do sentido dado ao termo consciência.

Quando o ser humano é enaltecido por Protágoras como a medida para todas as coisas, a partir da qual todo sentido é dado, passou a ser considerado representação subjetiva, como o sentido daquilo que antes era somente em si. Assim, tudo ficou mensurável ou passível de medida, segundo uma referência absoluta ao homem. $\mathrm{Na}$ Minima moralia ${ }^{2}$ em seu aforismo 39, é apresentada uma crítica ao critério de mensurabilidade. Por um lado, há um sentido para nós, mas este não se constitui em medida absoluta. Porém, uma vez tornada absoluta e admitindo nosso conteúdo de consciência como sendo a verdade real, abstraímos o outro de sua inscrição no mundo, gerando, com isso, a consequente redução epistemológica: "a recusa da verdade objetiva através

1 Principalmente matérias como educação física, na qual o professor e os alunos têm diante de si o corpo mesmo do outro; também em filosofia, em que o aluno é levado a compreender o mundo, o outro, a partir do critério racional e estético, ou seja, sensível; mas, com certeza, todas as disciplinas podem de alguma forma comprometer-se com isso.

2 As referências da obra Minima moralia serão apresentadas na seguinte ordem: nome do autor, ano de publicação, número do aforismo, seguido do número da página, conforme tradução ao português de Luiz Eduardo Bicca. 
do recurso ao sujeito implica a própria negação deste último: não resta nenhuma medida para a medida de todas as coisas" (Adorno, 1993, 39, p. 54).

Conteúdo de consciência tem relação com o "conteúdo de verdade", ${ }^{3}$ assim chamado o direcionamento que a obra de arte tem para com a realidade. Não é a verdade, mas um conteúdo desta, uma indicação da possibilidade de um real diferenciado. Do mesmo modo o conteúdo de consciência remete a uma possibilidade de significação subjetiva, longe de ser o conteúdo real mesmo. Pelo fato de a verdade e, consequentemente, todo o seu conteúdo ser determinado historicamente - grande ruptura com o pensamento metafísico -, falar em ampliação do nível de experiências formativas adquire legitimidade. $\mathrm{E}$ isso por um simples motivo: sendo histórico, é transitório, passível de constante metamorfose; então, a possibilidade de critério de medida partindo de uma experiência singular, determinada por um tempo e espaço petrificado, não encontra validade. Nossa experiência é tão histórica quanto o próprio fato observado e, assim, a teoria criada passa a ter os mesmos parâmetros de sentido real.É assim que Adorno e Horkheimer (1985, p. 9) definem sua elaboração teórica: "uma teoria que atribui à verdade um núcleo temporal, em vez de opô-la ao movimento histórico como algo de imutável".

Da tensão entre percepção - abertura à natureza externa - e expressão - entendida como ato de exteriorizar a natureza interna -, origina-se um núcleo cuja força pode assumir dupla perspectiva: estando munido de grande riqueza de conteúdo, surge a possibilidade de grande força expressiva ou, por outro lado, em posse de consciência malformada, e isto é a pobreza de conteúdo, a força de expressão não passa de repetição do sempre mesmo. Esse núcleo mencionado, a força de comunicação, nada mais é que a própria consciência. A tensão dialética propõe um constante renovar-se pela experiência com o outro - conforme proposta adorniana. Desse modo, e em sentido imediatamente inverso, ao tentar abocanhar o real mediante o conceito, aquele núcleo de força comunicativa perde seu impulso de esclarecimento.

Tal ocorrência se deve ao fato de que o esclarecimento somente tem sua possibilidade mediante o constante enfrentamento com a diversidade. Ao reduzir a diversidade, qualificada como mero manejo conceitual, revelamos, em síntese, traços de incomunicabilidade. Experiência que não se renova significa morte da diversidade, pobreza conceitual, enfraquecimento da força expressiva e consequente enfraquecimento da capacidade comunicativa - é a possível morte do sujeito. Nessa perspectiva deve ser entendida a dialética do esclarecimento, ao explicitarem-se os elementos promotores da ausência de força comunicativa, apontando para os aspectos possibilitadores da elevação do nível de experiências formativas. Por meio da capacidade comunicativa, visualiza-se, também, o sentido linguístico a ser considerado na educação, o que será desenvolvido no quinto capítulo deste ensaio.

3 Sobre "conteúdo de verdade", ver a obra adorniana denominada Teoria estética (s. d.). 


\section{AS PROPOSIÇÕES DE GADAMER}

O que significa o fim da metafísica, enquanto ciência? O que significa o seu finalizar em ciência? Se a ciência se elevar até uma tecnocracia total, cobrindo o céu com a "noite do mundo" do "esquecimento do ser", o nibilismo predito por Nietzsche, será que devemos ficar olhando atrás do último brilho de sol que se pôs no céu noturno, em vez de voltar-nos e procurar olhar para as primeiras cintilações de seu retorno? Gadamer, 2005, p. 25

Após o diagnóstico dos limites do paradigma cientificista que gerou o esquecimento do ser, Gadamer destaca a compreensão como uma experiência superior, para além da instrumentalização do método, capaz de revelar a verdade da obra de arte. Esta se revela como dimensão ontológica fundamental do ser, efetivando-se no horizonte da experiência histórica. Portanto, a verdade da obra de arte emerge não como artifício de técnica, mas como essência na compreensão, o que confere importância filosófica à arte. "Assim, ao lado da experiência da filosofia, a experiência da arte é a mais clara advertência para que a consciência científica reconheça seus limites” (idem, p. 31).

Convencido de que o sentido mais originário da experiência da obra de arte foi deixado de lado, quando concebida no âmbito da distinção estética, ${ }^{4}$ Gadamer afirma que tal abordagem não garante, suficientemente, o alcance da verdade. Mas esta pode ser alcançada tanto pela filosofia quanto pela experiência da arte, pois conformam, em si, a disciplina do perguntar e do responder, capaz de trazer à tona a verdade, antes velada. O que esse autor busca é compreender a verdade para além do monismo metodológico, no horizonte da experiência da obra de arte, como forma de liberar o perguntar do universalismo estrutural do método científico, que aceita "Ninguém" como sujeito, o sujeito abstrato. ${ }^{5}$

Nossa escolha por Gadamer se efetiva pelo fato de ele considerar a necessidade do diálogo profundo entre as tradições, entre os diferentes; por considerar amplamente a estética e buscar conjugar ética e estética como importantes elementos nos processos

4 Implica a impossibilidade da experiência estética, na medida em que a consciência, ou quem observa, não participa do processo, não entra no jogo, senão como um referencial externo que analisa.

5 Ao se referirem ao sujeito moderno, Adorno e Horkheimer (1985) revisam a trajetória de Ulisses em Odisseia e desbordam duas estratégias importantes desse herói: uma, sobre a passagem pelo vale das sereias, na viagem metafórica de Ulisses a Ítaca, em que ele ordena que os marinheiros tampem com cera os ouvidos, para não ouvir o canto das sereias, e que ele próprio seja amarrado ao mastro do navio para não sucumbir ao assédio desse ser; a outra, quando, astutamente, Ulisses decide passar a noite na terra dos ciclopes e se apresenta com Udéis, que significa "ninguém". Depois de se embriagar e estando adormecido, Ulisses fura o olho de Polifemo, que, ferido, urra de dor, clamando ajuda aos outros ciclopes. Mas como grita "Ninguém me feriu", os outros ciclopes voltam a dormir. Assim, Ulisses, mais uma vez, realiza a sua façanha. Dessa forma, a crítica de Adorno e Horkheimer esboça a estrutura da razão ocidental, que se institui como soberana e astuta (Matos, 1993). 
educativos, para além da crise da metafísica, como "consciência histórico-efeitual" (Gadamer, 2005).

\section{A INTERSUBJETIVIDADE DIALÓGICA: A FORMAÇÃO COMO AUTOFORMAÇÃO}

Em seu pano de fundo, o projeto gadameriano está pautado pelo problema da intersubjetividade, no contraponto com a subjetividade, base para a emergência daquela na mútua definição. "Poder-se-á até mesmo dizer que o conceito de intersubjetividade em geral só se torna compreensível se explicarmos anteriormente o conceito de subjetividade e de sujeito e o seu papel na filosofia fenomenológica" (Gadamer, 2007b, p. 11). Mas "foi enquanto um problema de todo o grande programa husserliano de uma fenomenologia transcendental que o conceito de intersubjetividade se tornou corrente" (idem, p. 9). Assim, analisando a problemática da subjetividade postulada por Husserl, criticada e desenvolvida por Heidegger, Gadamer verifica que tais posturas estão enunciadas em direções completamente diversas, por não tratarem corretamente o problema do outro. O primeiro anuncia a intersubjetividade, mas fica preso ao ideal de sujeito transcendental, abordando primeiramente o outro, o diferente sob o olhar mensurador, como objeto, para depois tê-lo enquanto outro. ${ }^{6}$ Já Heidegger denuncia esse acontecimento em Husserl, o que o fez avançar.

Conforme Gadamer, se em Heidegger a "relação-tu" depõe contra o kantismo contemporâneo e o ego transcendental, algo que Husserl preservou, Heidegger introduziu em Ser e tempo o conceito de "hermenêutica da facticidade". Tal conceito pode ser traduzido como o inatingível que resiste a toda tentativa de alcançar a transparência da compreensão, aproximando-se das proposições de Nietzsche de que não há verdade, mas interpretações. Diante do problema da subjetividade e da proposição da intersubjetividade, para Gadamer a crítica de Heidegger, comparada com a de Husserl, é mais contundente, pois, embora Husserl admita o mundo da vida, jamais se afastou do eu transcendental. Então, se em Husserl a percepção remonta à "certeza apodítica da autoconsciência" (Gadamer, 2007b, p. 17), a crítica de Heidegger visa à estreiteza de uma tal concepção de ser, evidenciando que, em Husserl, "a constituição fundamental primária do ser-aí humano é com isso desconhecida” (idem, p. 18).

Ainda de acordo com Gadamer (idem, p. 22), Heidegger não aborda o outro de forma adequada, a ponto de salvaguardar a subjetividade, porque em Heidegger “o ser-aí é tão originariamente ser-com, quanto ele é ser-aî". É nesse aspecto que está o problema heideggeriano, pois

[...] aquilo que é visto assim, no ponto de partida heideggeriano, no horizonte da questão do ser exclui tão radicalmente o primado da subjetividade, que o outro

6 Nas palavras de Gadamer (2007b, p. 21), “[...] Husserl insistiu no fato de o outro só poder ser dado inicialmente como coisa percebida e não na vitalidade, na dação corporal. É nesse ponto que começa a crítica ontológica heideggeriana à fenomenologia husserliana, no ponto de sua mais forte evidência. Tudo mostra-se aqui como se um conceito prévio de dação muito estreito - o conceito epistemológico de mensuralidade - tivesse obscurecido o gênio da descrição que Husserl no fundo era”. 
não pode absolutamente se transformar em problema. "Ser-aî" não é naturalmente subjetividade. Desse modo, em seu ponto de partida, Heidegger substituiu o conceito de subjetividade pelo conceito de cuidado. Nessa posição, contudo, fica claro que o outro só é visado com isso à margem e em uma perspectiva unilateral. (idem, ibidem)

Com base na citação anterior, observamos que o "ser-aî" heideggeriano não é naturalmente subjetividade, a subjetividade husserliana, expressão contemporânea do eu transcendental kantiano. Por isso, Gadamer postula que as duas compreensões não abordam de maneira adequada o problema da subjetividade. Em Husserl, o outro, primeiro, aparece como objeto, depois, como outro; em Heidegger, o outro aparece como ser-com, como indiferenciado. Mas não podemos esquecer que o próprio Gadamer sinaliza que a leitura heideggeriana de compreensão foi fundamental para ele, a exemplo da leitura aristotélica de ser como energia que, de acordo com o conceito moderno, possibilitou a compreensão em sua forma mais significativa, à luz da dimensão ontológica da obra de arte. ${ }^{7}$ Dessa forma, em Gadamer, a subjetividade é condição para a intersubjetividade e a intersubjetividade é condição para a subjetividade. Assim,

7 Conforme Gadamer, (2007a, p. 32-34), “[...] o que Heidegger empreendeu foi uma construção de Aristóteles como reflexo de suas próprias questões; e isso a fim de se assenhorear de suas próprias questões. [...] O exemplo é o termo grego para 'ser'. A palavra grega é ousia, tanto em Platão quanto em Aristóteles. [...] A língua alemã oferece algo que também estava de algum modo presente para o ouvido grego e para as suas expressões correspondentes: ousia significa propriedade presente (Anwesen). Ser é presença (Anwesenheit). [...] Ousia não é mais 'substância'. Essa era a tradução latina para hypokeimenon enquanto expressão formal para aquilo que subjaz. Essa expressão poderia designar o sentido do ser. 'Ser' é o 'que se acha diante de nós'. No entanto Aristóteles - ao lado dessa expressão formal - também concebeu o ser como energia e esse conceito se aproxima mais do conceito alemão de essência (Wesen) do que o conceito latino dominante na escolástica, o conceito de essentia (que conhecemos como 'essência' (Essenz) para um extrato vegetal não diluído)". Assim, Heidegger com sua leitura aristotélica desvendou a presença como energia, como "ser em obra", "ser em realização", o que permite pensar a vida em múltiplas direções. Mas diz Gadamer (idem, p. 38): "nós alemães ouvimos na palavra 'energia' (Energie) o carregamento explosivo da força acumulada. [...] Mesmo para os gregos, contudo, algo desse sentido também podia ser ouvido na palavra energia. Pois 'ser' não é apenas o ser substancial, aquilo que inevitavelmente se acha à nossa frente e que reside à base de todas as propriedades alternativas. Energia é muito mais o modo de ser daquilo que não é produzido por nós (ergon), mas daquilo que é 'por natureza', tal como os corpos simples". Assim, diferentemente da física moderna, que visa ao movimento enquanto tal e, portanto, movimento mensurável - o que define em essência (Essenz) o eu como autofundado e capaz de fundar em absoluto o desejado -, da leitura grega de Aristóteles, Gadamer absorve a noção de "ente em movimento". Mais que isso, conjuga as duas dimensões. 
o fortalecimento do outro contra mim mesmo descortina para mim pela primeira vez a possibilidade propriamente dita da compreensão. Deixar o outro viger contra si mesmo - e foi daí que surgiram todos os meus trabalhos hermenêuticos - não significa apenas reconhecer em princípio o caráter limitado do próprio projeto, mas exige precisamente que alcancemos um âmbito para além das próprias possibilidades no interior do processo dialógico, comunicativo, hermenêutico. (Gadamer, 2007b, p. 23-24)

Para descrever essa condição, o autor vale-se da metáfora do jogo. Diferentemente das duas posturas tensionadas por Gadamer, no jogo, não há predominância dos sujeitos que jogam, os jogadores, ao mesmo tempo, jogam e são jogados, pois o jogo ganha vida própria, revelando o ser como acontecer. Isso implica o fato de que não existe mais o mundo em que se vivia, pois também esse se transformou no jogo como jogo. Assim, o ser de todo jogo é sempre resgate, energia que traz o seu télos em si mesmo, posto que "o mundo da arte, no qual o jogo se manifesta plenamente na unidade de seu decurso, é, de fato, um mundo totalmente transformado. Nele toda e qualquer pessoa reconhece que 'assim são as coisas"” (Gadamer, 2005, p. 168). De tal modo, aquilo que pode ser separado do jogador, permanece enquanto tal, já que o jogo liberto da representatividade do jogador "tem o caráter de obra, do 'ergon' e não somente da "energia'. É nesse sentido que chamo de configuração" (idem, p. 165). Isso significa que conhecer não mais se efetua com base no dualismo clássico e de forma neutra, mas como um modo de ser, no horizonte do círculo hermenêutico ${ }^{8}$ em que o caráter dialogal da linguagem

ultrapassa o ponto de partida da subjetividade do sujeito, inclusive o do falante em sua referência ao sentido. $\mathrm{O}$ que se manifesta na linguagem não é a mera fixação de um sentido pretendido, mas um intento em constante mudança ou, mais precisamente, uma tentativa reiterada de deixar-se tomar por algo e com alguém. Mas isto não significa expor-se. A linguagem está longe de ser uma mera explicitação e credenciamento de nossos preconceitos. Ela os coloca, antes, em jogo, os expõe à própria dúvida e à contraposição do outro. [...]. Há algo mais [...] um potencial de alteridade, por assim dizer, que está além de todo o consenso comum. (Gadamer, 2004, p. 387)

Mas, é essa exigência presencial do eu e do outro como Dasein (como ser-no-mundo), como encontro entre diferentes, que produz o jogo dialógico no horizonte das perguntas e respostas, das proposições éticas e estéticas desde as tradições que se encontram e se desencontram, nunca chegando a uma síntese absoluta. "Nele [no

8 Em Gadamer $(2004$, p. 382), o círculo hermenêutico sugere que “[...] a estrutura do ser-no-mundo quer dizer a superação da divisão entre sujeito e objeto na analítica transcendental da pre-sença levada a cabo por Heidegger". 
círculo hermenêutico] não estamos encerrados como entre barreiras intransponíveis; ao contrário, estamos sempre abertos para o mundo" (Gadamer, 2005, p. 32).

É a própria pre-sença do eu e do outro que se constitui como o potencial da alteridade, que faz com que o interpretar e o compreender nunca se efetivem em uma única direção; consequentemente, nossas ações nunca se dão na unilateralidade, nem limitam os processos educativos à linearidade da lógica fechada. É no jogo como forma efetiva de diálogo que se ultrapassa a forma habitual de pensar que a essência do jogo é do âmbito da consciência do jogador, pois o jogo aparece enquanto jogo, enquanto diálogo acontecendo. E, se o diálogo é um jogo, o diálogo só "está em andamento quando o jogador singular entrega-se à seriedade absoluta do jogo" (Gadamer, 2000a, p. 124). Além do mais, a palavra existe, dizendo-se, e o diálogo produz a verdade, produzindo-se, não existindo uma primeira e última palavra. Contudo, é importante considerar que "a surpresa trazida pelo outro é uma espécie de impedimento da harmonização definitiva” (Fabri, 2006, p. 145).

Diferentemente do que ocorre com o sujeito cartesiano, no círculo hermenêutico a compreensão é autocompreensão, pois compreender é compreender-se no diálogo. É a ação em que a consciência emerge dentro da consciência de finitude, e não mais como transcendentalidade, como fora de. É a própria pre-sença, que como ser que é linguagem "sempre ultrapassa aquilo que nela se enuncia" (Gadamer, 2004, p. 386), pois a própria linguagem é experiência, é transformação em configuração. De outra maneira, em Gadamer, educar é educar-se no jogo dialógico, acontecer que se efetiva pela experiência profunda do homem consigo mesmo no viger do outro. Em consequência, as escolas, as salas de aula são o espaço do diálogo e os professores, os responsáveis diretos na promoção do ambiente dialógico, em que o plasmar linguístico possa ocorrer, ou seja, do círculo hermenêutico, do círculo da compreensão.

\section{CONFLUÊNCIAS ENTRE ADORNO E GADAMER}

$\mathrm{Na}$ sequência lógica deste ensaio, analisaremos as confluências possíveis entre os dois filósofos quanto às suas compreensões de mundo e de educação, visto ambos se efetivarem no âmbito da ruptura da metafísica, em que a educação foi profundamente afetada, suscitando novas reflexões.

Assim, se o pensamento metafísico pode ser caracterizado pela total antítese de estranhos e adversos com a consequente síntese na passividade da identidade, então, no pensamento pós-metafísico a total antítese não existe como força adversa e, portanto, não é passível de síntese enquanto paz no conceito. Isso nos leva a cunhar a expressão vontade de potência de alteridade, para expressar essa tendência de contraposição como uma força própria da vontade no encontrar e desencontrar com outras vontades, como intersubjetividade. Nesse processo, é a própria estrutura identitária que entra em jogo, mas sem vínculos de dependências capazes de subsumir-se ante o diferente e vice-versa. Isso revela uma mudança conceitual em relação à vontade pura de Kant 
e à vontade de pura potência em Nietzsche, situações em que o outro aparece ora como negação, ora como totalidade, estando o eu como princípio supremo de validade.

Considerando a perspectiva dialética, entendida como a renovada tensão com aquilo que é sempre outro, o diálogo entre os diferentes em que os conceitos, o eu e o outro, aparecem como diferença, como pré-conceito, a verdade aparece com resultado desse jogo, evidenciando o humano como histórico, como temporalidade. Isso ocorre tanto na perspectiva de Adorno quanto na de Gadamer, os quais coadunam na compreensão de ser enquanto "ergon" e "energia", herdada de Aristóteles, ou seja, "ser em obra"; os outros e os eus nunca aparecem em sua totalidade, mas enquanto modo de ser singular, revelando o ser como acontecer. Esse é o caráter enigmático da relação, apontando para a constante necessidade de reflexão, ao mesmo tempo em que configura o solo mais ou menos comum entre os dois filósofos. Sendo assim, esse processo de abertura é de extrema importância para a garantia de processos educativos que se constituem no âmbito da autonomia efetivada mediante o diálogo profundo entre os diferentes sujeitos dos processos.

Por conseguinte, o sujeito nunca é sujeito apenas de si, mas constituído e em constituição na perspectiva da intersubjetividade aberta. Do mesmo modo, a consciência nunca é apenas consciência de si mesma, como quis Hegel, mas consciências constituídas e constituintes enquanto intersubjetividade, sempre como elementos tensionados pelas diferenças que se projetam na emergência dos modos de ser, como experiência de finitude. Para Adorno (2005, p. 201), "O sujeito que supostamente é em si está em si mediado por aquilo do qual se separa, a conexão de todos os sujeitos. Através da mediação se converte ele mesmo naquilo que, segundo sua consciência de liberdade, não quer ser: heterônomo".

Nesses termos, as circunstâncias históricas nas quais o ser humano está inserido são as condições para constituir o si-mesmo, pois, para ser em-si, é necessário, também, ser com-outro. Servindo-nos da expressão "horizonte comum" (Hermann, 2010) e tendo presente a noção de educação no horizonte da construção linguística aqui proposta, sintetizamos, em termos adornianos, autoconstrução e horizonte comum e, em termos gadamerianos, autoformação e horizonte comum.

Com base no exposto, a educação nunca se efetivará como controle metodológico e epistemológico, mas no âmbito das experiências que nos remetem à possibilidade de emancipação, na medida em que se efetiva como autoformação. Isso asseguraria uma educação inscrita no evitar a barbárie na sua mais ampla acepção. E como fica a educação nessa perspectiva?

\section{A EDUCAÇÃO NO HORIZONTE DOS ENCONTROS}

É possível vislumbrar tanto com base em Adorno quanto em Gadamer o sentido formativo do ser humano a partir da perspectiva comunicativa ou linguística, que envolve todo encontro. É a comunicação de diferenciados e o ideal de construção, para o 
primeiro; é a própria linguagem, no segundo, como a tentativa de deixar-se tomar por algo ou por alguém, na própria experiência.

O primeiro conceito que precisa ficar evidente é o de construção, já que por meio dele será possível delinear o sentido educativo na perspectiva de construção da linguagem. Para Adorno (s. d.), na Teoria estética, a construção não implica o pleno domínio do processo construtivo por parte de apenas um lado da relação. Assim também o é em Gadamer (2005). A construção implica sempre o primado dos procedimentos construtivos em relação à imaginação subjetiva na intersubjetividade. A construção impõe soluções que o ouvido ou o olho que as representam não têm imediatamente presentes em toda a claridade. $\mathrm{O}$ imprevisto não só é efeito, mas possui igualmente um lado objetivo. Isso se encontra modificado numa nova qualidade.

O procedimento subjetivo de projetar um sentido, seguindo os ditames da imposição de algo sobre um objeto neutro e "imóvel", corresponde à anulação do caráter de novidade, de existência por si mesmo deste outro. Nesse sentido, ao dizer que o "imprevisto não só é efeito, mas possui igualmente um lado objetivo", podemos nos remeter ao próprio ideal de esperar pela manifestação do outro, a fim de gerar relação. Tal objetividade, entendida como esse vir do outro, esse projetar-se do outro em nossa direção, configura-se na nova qualidade da relação e aponta para a possibilidade de ser surpreendido pelo outro. Nesse mesmo sentido, Gadamer afirma que só por a obra de arte, o outro, ser algo em si e se apresentar numa perspectiva, é que pode haver diálogo e formação, o que não significa o predomínio do outro ou do eu.

O ato pedagógico está longe de ser algo monopolizado pela figura do professor, ou efetivado no âmbito da lógica linear tecnológica. Na construção das habilidades em sala de aula, na significação do conhecimento adquirido, não é raro o professor ser surpreendido pelo aluno, pela sua autoconstrução. Permitir essa experiência autoconstrutiva no âmbito dialógico, ou seja, no fio da linguagem, é o desafio de uma educação que ser quer de qualidade. Assim, a aula se efetiva em sua verdade quando instala o círculo da compreensão.

Hermann (2010, p. 120), defendendo o sentido pedagógico de autocriação e autoeducação, apresenta alguns vestígios da formação, os quais apontam para o mesmo caminho defendido neste ensaio: a) "a liberdade de experienciar a autoeducação ou autocriação de si"; b) a necessidade de "reconhecer a capacidade de luta do sujeito em se autoeducar, em saber que ele pode reagir para além de todas as adaptações”; c) a importância em preservar "a liberdade do indivíduo para determinar seu processo de formação"; d) o reconhecimento de que "a pessoa se constitui a si mesma num vínculo com o mundo, um trabalho feito com 'paciência e suavidade"”.

Tendo como base as noções de liberdade, reconhecimento, autoeducação e autocriação, indicados com base em Hermann, é possível vislumbrar o surgimento da categoria do novo, do inesperado, da surpresa que confirma nossa grandiosa riqueza constitutiva. O novo é aquilo que surge no momento em que estamos conscientes do controle do processo, aquilo que surge quando percebemos estar entendendo o 
desenrolar da ação, e que nos faz perceber os limites da estrutura racional prévia e fixa, bem como de todo ato pautado por tal estrutura. Na categoria do novo, reside o indicativo ético da alteridade, na medida em que traz no seu seio a vontade de potência de alteridade, porque "todo jogar é um ser-jogado" (Gadamer, 2005, p. 160, grifo do autor) e, no jogo, não há o domínio de uma dada subjetividade, senão que a subjetividade do jogo. Assim como na obra de arte, o ato pedagógico enquanto ofício produtivo, criador, deve "conter características, as quais, no processo de produção, não são previsíveis; e que, subjetivamente, o artista era surpreendido pelas suas próprias obras"(Adorno, s. d., p. 51).

Essa forma de compreender o ato pedagógico-construtivo, ou dialógico como em Gadamer, que se efetiva no círculo hermenêutico, não só dissolve o momento da unidade imposta desse querer em elemento polido e harmonioso, logicamente aceito, como possibilita o ser para o ser. Dissolve-se a postura antiética e, por isso mesmo, desumana, de construção enquanto montagem e composição - ato, tão somente, de um sujeito sobre um objeto, como ocorre, metaforicamente, no jogo de lego. Valendo-nos, ainda, da relação com a arte, a qual "nos indica que o mundo não é plenamente compreendido no âmbito conceitual e que pode deixar um espaço para uma promessa de vida"(Hermann, 2010, p. 45), a educação deveria ser a primeira a respeitar e permitir a realização dessa promessa.

Cientes do sentido que a construção assume no interior da teoria filosófica dirigida à educação, remetemos, agora, ao construir, ou plasmar, da linguagem como sendo o desafio educacional que a sala de aula deveria assumir. Seguindo as linhas de Gadamer (1983b, p. 11), a linguagem deve ser entendida como algo que "não é um mero instrumento ou um dom excelente que possuímos como homens, mas o meio no qual vivemos desde o começo, como seres sociais, e que mantém aberto o todo no qual existimos". Desse modo, "cada vez que se leva a cabo uma comunicação, não só se usa, como também se plasma a linguagem” (idem, p. 12).

Seguindo essas linhas, podemos afirmar que o ser humano não usa a linguagem, ele é linguagem, é comunicação que se produz no diálogo efetivo, ou seja, que possibilita a autotransformação, ou autoconstrução dos envolvidos - o que significa, em última instância, o plasmar do humano, o plasmar da linguagem. Como mundo munda, conforme Heidegger; na perspectiva de Gadamer, o humano humana. Isso porque, "não só o mundo é mundo apenas quando vem à linguagem, como a própria linguagem só tem a sua verdadeira existência no fato de que nela se representa o mundo" (Gadamer, 2005, p. 572). De outra forma, a linguagem não está aí como um simples aparato do qual lançamos mão ou como uma convencionalidade que construímos para nos comunicar, senão que

Antes, pertence à própria experiência o fato de ela buscar e encontrar as palavras que a expressem. Buscamos a palavra certa, isto é, a palavra que realmente pertença à coisa, de modo que ela própria venha à fala. Embora afirmemos que isso não 
implica uma simples relação de cópia, a palavra pertence de tal modo à própria coisa que não é atribuída posteriormente à coisa como signo. (idem, p. 539)

À medida que a palavra "subordinar" empresta seu sentido idealizado ao jogo articulador da experiência, a linguagem como medium faz emergir o logos. Dito de outra forma, a palavra não é apenas mera convenção para representar a coisa nem pura expressão da coisa; "mostra uma certa vinculação com aquilo que é 'reproduzido' (Abgebildete), uma pertença ao ser do que é reproduzido” (idem, p. 538). A palavra somente ganha sentido na atualidade do seu uso, como acontece ao conjugar ergon e energia. "Palavra e língua são aquilo com o que lidamos uns com os outros e com o mundo no qual estamos em casa [...]. O mistério da linguagem é a sua abertura" (Gadamer, 2007a, p. 45).

Nós somos a palavra, a linguagem; nós não a usamos, nela vivemos: "as palavras que usamos na linguagem nos são a tal ponto familiares que estamos aí, por assim dizer, nas palavras. Elas não se tornam objeto. $\mathrm{O}$ uso da língua não é de modo algum o uso de algo. Nós vivemos em uma língua como em um elemento, como o peixe na água" (Gadamer, 2007c, p. 95).

Diante disso, vislumbramos o real desafio que é a sala de aula: ela deve ser o espaço do plasmar esse mundo, esse elemento no qual vivemos. Pela construção da linguagem é possível produzir sentido, gerar sentido; por essa construção, a própria escola passa a ter sentido, convertendo-se em espaço comum no qual constituímos modos de compreender o mundo. É possível afirmar que, ao questionarmos a qualidade da educação, necessariamente a importante resposta que encontraremos contemplará essa construção.

Retornando às discussões sobre pergunta e resposta,já iniciadas no item anterior, devemos ter presente que toda pergunta desestabiliza, pois, para corresponder à ânsia do interrogante, é necessário, a fim de compreendê-lo, que estejamos em sintonia linguística, habitemos o mesmo mundo de signos e, também, tenhamos lucidez do espaço ocupado pelo outro.

Se temos de dar resposta a uma pergunta que não conseguimos entender corretamente, isto é, se não sabemos o que o outro quer saber, temos obviamente que procurar entender melhor o sentido da pergunta. Só quando compreendi o sentido motivador da pergunta posso começar a buscar uma resposta. [...] Esta é a primeira exigência básica, de alcance infinito, que se propõe a todo esforço hermenêutico. [...]. Este deve ser nosso primeiro objetivo ao nos defrontarmos com uma pergunta. Para formular isto com palavras de nossa experiência trivial: temos que compreender o que é que se esconde atrás da pergunta que se propôs. (Gadamer, 1983c, p. 73)

Isso é interpretação, é conseguir atualizar a fala, o texto, para o exato momento em que ocorre a experiência, o que se manifesta na interlocução entre os modos 
de ser. Somente quando conseguimos compreender o desafio que vem do outro, da reivindicação, da pergunta que o outro é, somente nesse instante possibilitamos a experiência efetiva da resposta e do plasmar linguístico em sala de aula como experiência hermenêutica. Seu

campo primordial é a experiência ontológica do encontro com o outro e a linguagem que se efetua no diálogo. Por depender do diálogo vivo, a busca da verdade efetua-se no vaivém das considerações e dos raciocínios de seus integrantes, os quais trazem consigo, cada um, a carga de visões do mundo e de sentidos particulares, portanto diferentes. É, porém, justamente a partir dessa carga que nascem as perguntas. (Flickinger, 2011, p. 2)

Para quem está em interlocução, há certo desconforto causado pela concretude dessa situação, uma irritação pelo fato de o interlocutor ser possuidor de razão, por ele ser tão capaz de compreensão quanto nós. Em consequência, à educação é imposto o compromisso de considerar o local, a linguagem na qual o outro vive; que, nessa relação,

A pedagogia terá de levá-lo [o diálogo] a sério, se o processo pedagógico não quiser esgotar-se na mera transmissão de conhecimentos e na qualificação profissional. Ela deveria promover, antes de tudo, a oportunidade de o educando e o educador entregarem-se a uma situação aberta, a um diálogo que, além de trabalhar determinados conteúdos, se processa como relação social; ou seja, como relação de desafio, no sentido de fazer do vir ao encontro do outro o campo de aprendizagem intersubjetivo e, por isso mesmo, ético-moral. (idem, p. 6-7)

A educação entendida como situação aberta indica sua característica social e histórica. A história, em sua transitoriedade, tem o poder de derrubar visões dogmáticas, mostrando a dinâmica que envolve a vida em todas as suas instâncias (pessoais, interpessoais, biológicas, psíquicas). $\mathrm{O}$ mesmo ocorre em termos sociais, quando a linearidade de projetos nem sempre se harmoniza com a dinâmica dessa mesma sociedade. E a educação como ato social também sofre a ação de forças opostas, pondo em cheque as certezas e seguranças dos envolvidos. Parafraseando Flickinger (idem), estamos diante da lógica clandestina da ação humana, em que não há uma linearidade entre o pensado, o planejado, o escrito e o feito. Por isso não é raro termos bons propósitos barrados por sua própria dinâmica - a ação acaba sendo o próprio sujeito, independente, muitas vezes, do próprio sujeito humano.

Finalizando, retornamos ao conceito de compreensão e, citando Hermann (2010, p. 117), destacamos que a "autêntica experiência implica acumular compreensões". Relacionada a esse acúmulo de compreensões está a noção de ausência de evidência e consciência em Adorno (s. d.).

Pelo fato de não ser mera imitação da realidade, a arte se constitui como permanente interrogação à razão, de modo que um único olhar, ou uma única experiência, 
não consegue gerar a lucidez de consciência necessária ao indivíduo. Esse caráter de ausência de evidência nos põe diante do limite da compreensão, quando o sentido não está posto à razão de modo imediato, exigindo o esforço de sempre renovar a experiência e, consequentemente, acumular compreensão. Tal acúmulo pode, então, referir-se às diversas interfaces geradas nos instantes comunicativos, ou seja, nos instantes em que nos deparamos com a diversidade do outro. Não é algo meramente quantitativo em um simples aglomerado de compreensões sem interconexões. Em virtude do constante renovar das provocações do outro e da constante necessidade de a razão admitir a renovação de seus conteúdos, a verdade vai surgindo nesse processo de gerar compreensões, uma após a outra, em uma permanente evolução de consciência. Essa é a perspectiva que vislumbramos nos atos educativos, quando

não basta conhecer elementos típicos do comportamento da pessoa para, então, predizer seu agir. [...] Outra maneira de compreender e experimentar o tu é reconhecê-lo como pessoa [...]. Essa forma de experiência não pretende que o conhecimento das pessoas sirva para controlá-las, mas, antes disso, desencadeia um processo compreensivo que exige quebrar nossas resistências para se abrir ao outro, para deixar valer a palavra do outro. $\mathrm{O}$ encontro com a alteridade nos enriquece ao integrar o que nos falta, ao experimentar que nem sempre o que sabemos é suficiente para compreender a situação. (Hermann, 2010, p. 117)

A experiência de professor, em sala de aula, é marcada por essa quebra de resistências ao outro, do outro, por deixar-se invadir pela sua riqueza constitutiva, participando no permanente projeto de permitir sua autoconstrução, sua autoformação, a autoeducação. Educar, ensinar, formar, tudo isso não é meio de controle, mas, em primeiro lugar, concordando com Hermann, é o desencadear de um processo de compreender o outro, sua alteridade, e também compreender a si próprio no momento em que a situação se estabelece. Em síntese, é o desencadear da qualidade educacional tão necessária no nosso contexto atual, marcado pela fragmentação das relações, pela prioridade nas informações e não no conhecimento. Nesse sentido, a ação docente pode se converter em um processo de conhecimento de si, de constituição da identidade dos diversos agentes que se conectam na ação pedagógica.

\section{CONSIDERAÇÕES FINAIS}

As investigações sobre a educação no horizonte da construção linguística reverberam nas práticas pedagógicas, mostrando tanto o fracasso de algumas práticas, quanto o sucesso em que o espaço sala de aula pode se converter. Compreendendo a linguagem como o meio no qual vivemos e a partir do qual nos expressamos e somos, o meio que nos identifica e constrói, é possível visualizar os motivos que conduzem ao fracasso as pretensões de ensino e educação. Enquanto professores e alunos, alunos e 
alunos, comunidade escolar como um todo não conseguirem plasmar, construir, formar esse meio comum, qualquer iniciativa não surtirá os efeitos positivos esperados.

Em outras palavras, precisamos falar a mesma linguagem, não somente como um mesmo conjunto de signos, mas como possibilidade de compreensão do outro, valorização do local de onde ele fala. Trata-se de uma condição capaz de permitir ao humano ser o responsável pela sua própria constituição. Precisamos construir o meio linguístico, o que não é feito arbitrariamente, mas pressupõe autoridade esclarecida sobre sua verdadeira função: garantir ao outro realizar suas experiências formativas e, consequentemente, constitutivas de si mesmo em conexão com o si mesmo do outro. Somente quando a sala de aula se converter nesse espaço de plasmar linguístico, no sentido defendido neste ensaio, é que poderemos reconhecê-lo como o local privilegiado no desenvolvimento das pessoas.

Construir é disponibilizar a riqueza de experiências e se abrir à novidade que vem do outro; é participar do processo como um dos agentes envolvidos, o que exige algo bem simples, porém muito desafiador: conseguir se demorar na relação. Em questões de conhecimento, o demorar na relação é muito importante, pois não conseguimos compreender uma obra, construir conhecimento, apressadamente; ao contrário, o processo do conhecimento exige exaustiva e permanente dedicação. $\mathrm{O}$ mesmo se verifica com referência à educação. Precisamos ensinar, no sentido amplo do termo, a "parar"e tratar o outro como alguém que não se reduz a uma compreensão prévia, apressada, mas sim, dialogada. Esse é um modo de compreender a hermenêutica gadameriana em sua aplicação ao âmbito pedagógico, além de ser um modo de compreender formação da consciência em Adorno como o grande problema da educação tanto escolar quanto a que se estabelece em todos os momentos da vida do ser humano.

Então, voltando à pergunta orientadora, pontuada na introdução, ou seja, os termos nos quais a educação pode responder às exigências que envolvem a formação do humano, a resposta pode ser delineada em torno da conjunção de dois termos fundamentais: a construção em Adorno, e o plasmar em Gadamer. Dirigido à linguagem, temos a construção linguística ou o plasmar linguístico como o horizonte comum a ser percorrido em sala de aula.

\section{REFERÊNCIAS}

Adorno, Theodor Ludwig Wiesengrund. Minima moralia: reflexões a partir da vida danificada. Tradução de Luiz Eduardo Bicca. 2. ed. São Paulo: Ática, 1993.

. Observações sobre o pensamento filosófico.In: . Palavras e sinais: modelos

críticos 2. Tradução de Maria Helena Ruschel. Petrópolis: Vozes, 1995. p. 15-25.

. Educação e emancipação. Tradução de Wolfgang Leo Maar. 3. ed. São Paulo: Paz e Terra, 2003. 
Dialética negativa. Tradução de Alfredo Brotons Muñoz. Madrid: Ediciones Akal, 2005. (Obra Completa, 6)

. Teoria estética. Tradução de Artur Morão. Lisboa: Edições 70, s.d. (Arte e Comunicação, n. 14)

Adorno, Theodor Ludwig Wiesengrund; Horkheimer, Max. Dialética do esclarecimento: fragmentos filosóficos. Tradução de Guido Antonio de Almeida. Rio de Janeiro: Jorge Zahar Editor, 1985.

Aristóteles. Metafísica. Ed. trilíngue por Valentín García Yebra. 2. ed. rev. Madrid: Editorial Gredos, 1982.

FABRI, Marcelo. Harmonização e estranhamento: a proposta de uma fenomenologia responsiva. In: Trevisan, Amarildo Luiz; Tomazetti, Elizete M. (Orgs.). Cultura e alteridade: confluências. Ijuí: Unijuí, 2006. p. 143-155.

Flickinger, Hans-Georg. A caminho de uma pedagogia hermenêutica. Campinas: Autores Associados, 2011. (Coleção Educação Contemporânea)

Gadamer, Hans-Georg. Acerca da disposição natural do homem para a filosofia. In: . A razão na época da ciência. Tradução de Ângela Dias. Rio de Janeiro: Tempo Brasileiro, 1983a. p. $78-87$ (Biblioteca Tempo Universitário, 72)

. Acerca do filosófico nas ciências e do científico na filosofia. In: . A razãa na época da ciência. Tradução de Ângela Dias. Rio de Janeiro: Tempo Brasileiro, 1983b. p. 9-25 (Biblioteca Tempo Universitário, 72)

. Hermenêutica como filosofia prática. In: . A razão na época da ciência. Tradução de Ângela Dias. Rio de Janeiro: Tempo Brasileiro, 1983c. p. 57-77 (Biblioteca Tempo Universitário, 72)

. Homem e linguagem. In: Almeida, Custódio Luís Silva de; Flickinger, Hans-Georg; Rohden, Inácio (Orgs.). Hermenêutica filosófica: nas trilhas de Hans-Georg Gadamer. Porto Alegre: EDIPUCRS, 2000a.

. La educación es educarse. Tradução de Francesc Pereña Blasi. Barcelona; Buenos Aires; México: Paidós, 2000b.

. Verdade e método II: complemento e índice. Tradução de Enio Paulo Giachini; Revisão da tradução de Marcia Sá Cavalcante Schuback, 2. ed. Petrópolis: Vozes; São Paulo: Editora Universitária São Francisco, 2004.

.Verdade e método I: traços fundamentais de uma hermenêutica filosófica. Tradução de Flávio Paulo Meurer; nova revisão da tradução de Enio Paulo Giachini.7.ed.Petrópolis: Vozes; São Paulo: Editora Universitária São Francisco, 2005.

. Ciência histórica e linguagem. In: .Hermenêutica em retrospectiva: a posição da filosofia na sociedade. Tradução de Marco Antônio Casanova. Petrópolis: Vozes, 2007a. p. 59-68 (Coleção Textos Filosóficos, v. IV)

. Hermenêutica em retrospectiva: Heidegger em retrospectiva. Tradução de Marco Antônio Casanova. Petrópolis: Vozes, 2007b. v. I. 
. Pensar com a língua. In: Hermenêutica em retrospectiva: a posição da filosofia na sociedade. Tradução de Marco Antônio Casanova. Petrópolis: Vozes, 2007c. p. 91-100 (Coleção Textos Filosóficos, v. IV)

Subjetividade e intersubjetividade, sujeito e pessoa (1975). In:

Hermenêutica em retrospectiva: a virada hermenêutica. Tradução de Marco Antônio Casanova. Petrópolis: Vozes, 2007d. v. II, p. 9-27.

Giacoia Junior, Oswaldo. Nietzsche. São Paulo: Publifolha, 2000.

Hermann, Nadja. Pluralidade e ética em educação. Rio de Janeiro: DP\&A, 2001.

. Autocriação e horizonte comum: ensaios sobre educação ético-estética. Ijuí: Unijuí, 2010. (Coleção Fronteiras da Educação)

Kant, Immanuel. Fundamentação da metafísica dos costumes. Tradução de Paulo Quintela. Lisboa: Edições 70, 2008.

Matos, Olgária. Escola de Frankfurt. luzes e sombras do Iluminismo. São Paulo: Moderna, 1993.

Nietzsche, Friedrich. Sujeito e perspectivismo. Seleção de textos de Nietzsche. Notas introdutórias de Antonio Marques. Portugal: Publicações Dom Quixote, 1989.

\section{SOBRE OS AUTORES}

Clenio Lago é doutor em educação pela Pontifícia Universidade Católica do Rio Grande do Sul (PUC-RS). Professor da Universidade do Oeste de Santa Catarina (UNOESC).

E-mail: cleniolago@yahoo.com.br

Mauricio João Farinon é doutor em educação pela Pontifícia Universidade Católica do Rio Grande do Sul (PUC-RS). Professor da Universidade do Oeste de Santa Catarina (UNOESC).

E-mail:mauriciojfarionon@gmail.com 
